\title{
Communities of practice in the school workplace
}

\author{
Citation for published version (APA):
}

Brouwer, P., Brekelmans, M., Nieuwenhuis, A. F. M., \& Simons, R-J. (2012). Communities of practice in the school workplace. Journal of Educational Administration, 50(3), 346-364.

https://doi.org/10.1108/09578231211223347

DOI:

10.1108/09578231211223347

Document status and date:

Published: 04/05/2012

Document Version:

Publisher's PDF, also known as Version of record

Please check the document version of this publication:

- A submitted manuscript is the version of the article upon submission and before peer-review. There can be important differences between the submitted version and the official published version of record. People interested in the research are advised to contact the author for the final version of the publication, or visit the DOI to the publisher's website.

- The final author version and the galley proof are versions of the publication after peer review.

- The final published version features the final layout of the paper including the volume, issue and page numbers.

Link to publication

\section{General rights}

Copyright and moral rights for the publications made accessible in the public portal are retained by the authors and/or other copyright owners and it is a condition of accessing publications that users recognise and abide by the legal requirements associated with these rights.

- Users may download and print one copy of any publication from the public portal for the purpose of private study or research.

- You may not further distribute the material or use it for any profit-making activity or commercial gain

- You may freely distribute the URL identifying the publication in the public portal.

If the publication is distributed under the terms of Article 25fa of the Dutch Copyright Act, indicated by the "Taverne" license above, please follow below link for the End User Agreement:

https://www.ou.nl/taverne-agreement

Take down policy

If you believe that this document breaches copyright please contact us at:

pure-support@ou.nl

providing details and we will investigate your claim.

Downloaded from https://research.ou.nl/ on date: 26 Apr. 2023 


\section{e emeraldinsight}

\section{Journal of Educational Administration}

Communities of practice in the school workplace

Patricia Brouwer Mieke Brekelmans Loek Nieuwenhuis Robert-Jan Simons

\section{Article information:}

To cite this document:

Patricia Brouwer Mieke Brekelmans Loek Nieuwenhuis Robert-Jan Simons, (2012),"Communities of practice in the school workplace", Journal of Educational Administration, Vol. 50 Iss 3 pp. 346 - 364

Permanent link to this document:

http://dx.doi.org/10.1108/09578231211223347

Downloaded on: 26 March 2017, At: 00:59 (PT)

References: this document contains references to 45 other documents.

To copy this document: permissions@emeraldinsight.com

The fulltext of this document has been downloaded 1883 times since $2012^{*}$

\section{Users who downloaded this article also downloaded:}

(2014),"Developing strategies for communities of practice", International Journal of Educational

Management, Vol. 28 Iss 6 pp. 751-764 http://dx.doi.org/10.1108/lJEM-07-2013-0105

(2008),"Improved organizational performance through communities of practice", Journal of Knowledge Management, Vol. 12 Iss 1 pp. 106-118 http://dx.doi.org/10.1108/13673270810852421

Access to this document was granted through an Emerald subscription provided by emerald-srm: 302097 []

\section{For Authors}

If you would like to write for this, or any other Emerald publication, then please use our Emerald for Authors service information about how to choose which publication to write for and submission guidelines are available for all. Please visit www. emeraldinsight. com/ authors for more information.

\section{About Emerald www.emeraldinsight.com}

Emerald is a global publisher linking research and practice to the benefit of society. The company manages a portfolio of more than 290 journals and over 2,350 books and book series volumes, as well as providing an extensive range of online products and additional customer resources and services.

Emerald is both COUNTER 4 and TRANSFER compliant. The organization is a partner of the Committee on Publication Ethics (COPE) and also works with Portico and the LOCKSS initiative for digital archive preservation.

*Related content and download information correct at time of download. 
JEA

50,3

\section{6}

Received 1 November 2010

Revised 14 January 2011

12 April 2011

19 June 2011

Accepted 20 June 2011

\section{Communities of practice in the school workplace}

Patricia Brouwer

Centre for Expertise in Vocational Education and Training, Utrecht, The Netherlands

Mieke Brekelmans

Faculty of Social and Behavioural Sciences, Utrecht University, Utrecht, The Netherlands

Loek Nieuwenhuis

Rund de Moor Centre, Open University, Heerlen, The Netherlands, and

Robert-Jan Simons

Centre for Teaching and Learning, Utrecht University, Utrecht, The Netherlands

\begin{abstract}
Purpose - The first aim of this study is to explore to what extent communities of practice occur in the school workplace. The second aim is to explore the relation between communities of practice and diversity in composition of teacher teams.

Design/methodology/approach - Quantitative as well as qualitative data were gathered from seven teacher teams in a school for secondary education. Questionnaires and observation instruments were used to measure and analyze teacher teams' collaborative activities and diversity in composition.

Findings - Data suggest that communities of practice actually occur in the school workplace, but to a moderate extent. Also, communities of practice are related to four of the five diversity attributes that were investigated.

Research limitations/implications - The current study is a snapshot measurement of communities of practice. Future research is recommended to focus on the development of communities of practice in the school workplace by including longitudinal measurements.

Practical implications - Implications for teachers and administrators include follow-up activities aimed at stimulating and sustaining communities of practice as well as taking diversity considerations in team composition into account.

Originality/value - Studies suggest that a community is a promising context for embedding collaboration into the culture of the school. However, empirical research that focuses on communities in the school workplace seems largely absent. This study provides insight in the occurrence of communities of practice from two perspectives: the perception of community members and the observation from outsiders.
\end{abstract}

Keywords Communities, Secondary schools, Community of practice, Team composition, Team diversity, Teachers, The Netherlands

Paper type Research paper

The authors wish to acknowledge the work and contribution of their colleagues from the research team, namely Wilfried Admiraal, Sanne Akkerman, Jos Beishuizen, Marjolein Dobber, Rick de Graaff, Ditte Lockhorst, Albert Pilot, Inne Vandyck, Nico Verloop and Jan Vermunt. The authors would like to thank the teachers in this project, who gave their time generously. The authors would also like to thank the anonymous reviewers for their helpful comments on an earlier version of this manuscript. This research is funded by The Netherlands Organization for Scientific Research, Dutch Programme Council for Educational Research: 411-05-351.
Journal of Educational

Administration

Vol. 50 No. 3, 2012

pp. $346-364$

(c) Emerald Group Publishing Limited 0957-8234

DOI 10.1108/09578231211223347 


\section{Introduction}

Internationally, schools for secondary education have seen themselves confronted with reforms pertaining to changing curriculum frameworks, new designs for teacher professional development and the changing role of teachers. More specifically, reforms that underlie the increase in collective action between teachers include collective teaching, coherence between subject areas, and distributed decision making. These reforms call for consultation and coordination between teachers. Teachers need to share responsibility and authority for decision-making about their common practices (Hargreaves and Dawe, 1990). Therefore, to deal with recent reforms and the accompanying complexity of work, ongoing collaboration between teachers has become more important.

In recent years, teacher collaboration has received more attention from scholars as teachers work in a less isolated manner nowadays (Hargreaves and Dawe, 1990). An array of scholars and reformers has called for the strengthening of collaboration between teachers by means of promoting communities of teachers in schools (Levine and Marcus, 2010; James et al., 2007). The term "communities of teachers' refers to 'teachers' collective engagement in sustained efforts to improve practices" (Louis et al., 1996, p. 758). An argument for promoting communities of teachers is that communities foster collaboration to be more than an occasional exchange between teachers. Communities embed teacher collaboration into the culture of the school (Vescio et al., 2008), making collaboration expected, inclusive, genuine, and ongoing (Seashore et al., 2003). This is illustrated by a study by Bolam et al. (2005), in which teachers reported an increase in collaboration as they worked in communities. This evidence suggests that a community is a promising context for stimulating ongoing collaboration between teachers and embedding collaboration into the school culture.

Even though there is growing awareness of the potentially strong role of communities, the research base on communities of teachers is sparse (Imants, 2003; Westheimer, 1999). First, there seems to be a lack of conceptual clarity on communities of teachers (Westheimer, 1999; Vescio et al., 2008). Consequences are that concepts of community vary widely among scholars, also, there is little agreement among teachers and administrators as to whether teacher communities actually occur within their school. Second there seems to be an absence of empirical research about teacher communities in the school workplace (Westheimer, 1999). Hence, the first aim of this study is to explore whether and to what extent communities of teachers actually occur in the school workplace. To this end this study investigated to what degree teacher teams in secondary education demonstrated characteristics of a teacher community. Teacher teams are jointly responsible for the work of teaching as well as team performance (Main and Bryer, 2005). We used the conceptual framework of Wenger (1998), in which communities are defined along the dimensions mutual engagement, shared repertoire, and joint enterprise.

The second aim of this study is to explore the relation between diversity in team composition and teacher communities. Hence, we investigated whether there is a relation between teacher communities and diversity in team composition. Although many scholars have studied the relationship between team diversity and team functioning, few empirical studies have investigated the role of diversity in teacher teams in the school (Drach-Zahavy and Somech, 2002). Looking at the body of

\section{Communities of} practice

347 
JEA

50,3

348

literature, the educational context seems to be under-examined in studies about diversity in team composition.

Studies on team functioning and diversity in team composition have indicated the potential of diversity in team composition for team processes as well as for team outcomes. Meta-analytic studies by Horwitz and Horwitz (2007), Webber and Donahue (2001), Stewart (2006), Bowers et al. (2000) and review studies by Jackson (1996, 1992) show inconsistent findings with regard to the effect of diversity in teams. Scholars talk of the "double-edged sword" that is diversity. On the one hand, there is evidence for the value of diversity in team composition (Bowers et al., 2000). The theoretical arguments supporting diversity focus on the creativity associated with diverse viewpoints and skill-sets in a team (Stewart, 2006). On the other hand, there is evidence for the positive effect on processes and outcomes of similarity in team composition (Bowers et al., 2000). Arguments supporting similarity focus on the notion that highly similar people experience less conflict (Stewart, 2006). With regard to these ambiguous findings, scholars recommend not studying diversity not as a generic concept, but distinguishing between types of diversity. There is uncertainty with regard to which types of diversity are beneficial for team processes and outcomes (Stewart, 2006). To conclude, it seems that there is added value in distinguishing between different diversity types when studying diversity in the educational context.

\section{Theoretical framework}

Communities of teachers

Works by Quinn $(1981,1988)$ have developed a framework to understand social processes in teacher teams from a cultural perspective. Team culture is defined as a shared belief and value systems with regard to social reality including aims, decision-making processes, leadership style, evaluation and motivation (Shapira-Lishchinsky, 2009). Quinn distinguishes four team culture dimensions:

(1) group, which emphasizes the group and cooperation in decision-making;

(2) developmental, which emphasizes innovation and creativity;

(3) hierarchical, which emphasizes rules, stability and orderly decision-making processes; and

(4) rational, which emphasizes productivity and efficiency, alongside planning and management according to targets.

The community of practice perspective provides opportunities to specifically identify the culture of practice (Wenger, 1998) of a teacher team. As teacher teams usually develop around a shared work objective (Skerrett, 2010), they are "about" something. The domain (topic of mutual interest, passion) of the team gives the team an identity, and the commitment to care for this domain gives it cohesiveness and intentionality (Wenger et al., 2002). Works by Jean Lave and Etienne Wenger have developed the concept of communities of practice to describe sites where people jointly construct, transform, conserve, and/or negotiate the meanings of practices (Lave and Wenger, 1991; Wenger, 1998; Wenger et al., 2002). Communities of practice are groups of people who share a concern or a passion for something they do and learn how to do it better as they interact regularly. Over time, community members develop a common sense of identity, they develop personal relationships and established ways of interacting and 
they also develop a unique perspective on their topic as well as a body of common knowledge, practices and approaches. A community of practice defines itself along three dimensions, mutual engagement, shared repertoire, and joint enterprise (Wenger, 1998).

(1) The mutual engagement binds members of the community together into a social entity. Mutual engagement creates relationships among members; it connects them in ways that can become deeper than more superficial similarities in terms of personal features or social categories. Being included in "what matters" in a group is a requirement for being engaged in a community's practice.

(2) Community members develop a shared repertoire, a shared set of communal resources such as routines, words, tools, ways of doing things, stories, and concepts. The concepts, language and tools embody the history of the community and its perspective on the world. The repertoire of a community is a resource for the negotiation of meaning.

(3) The joint enterprise is the collectively developed understanding of what the community is about. The joint enterprise is the result of a collective process of continuous negotiation and it creates among participants' relations of mutual accountability that become an integral part of the practice.

A practice-oriented conception of collaborative processes in teacher teams seems most suitable in this study. Hence, the conceptual framework of Wenger (1998) is used.

\section{Degree of mutual engagement, shared repertoire, and joint enterprise}

To investigate to what degree teacher teams demonstrate characteristics of a community of practice, a measurement-based approach is used. That is, the degree in which the dimensions of a community of practice are present was measured. However, there is no indication in the literature about where to draw an absolute standard as to what limited, moderate and strong (Admiraal and Lockhorst, 2010) degrees of mutual engagement, shared repertoire, and joint enterprise are. de Lima (1998) offers two possibilities for solving this problem. The first possibility is to draw a measure that is defined relative to a value judgment about what is limited, moderate or strong. The second possibility is to use a value abstracted from the data that are available as a standard for comparison and classification (de Lima, 1998).

The following research question was formulated:

RQ1. To what degree do teacher teams in a school for secondary education demonstrate mutual engagement, shared repertoire, and joint enterprise?

\section{Diversity in team composition}

The concept of diversity refers to the variation in team members' individual characteristics. Diversity is about the social composition of a team (Drach-Zahavy and Somech, 2002; Jackson, 1996). Frequently used categories of diversity are task-related diversity and relations-oriented diversity (Webber and Donahue, 2001). Task-related diversity attributes are specific skills and abilities needed to perform an educational job. Relations-oriented diversity attributes are innate team member characteristics (Drach-Zahavy and Somech, 2002; Jackson, 1996). Theoretical notions regarding diversity and similarity in team composition imply that task-related diversity will
Communities of practice

349 
JEA

50,3

350

increase positive team functioning because it broadens the resources of the team that are relevant to task performance and increases its ability to engage in more complex problem-solving (Webber and Donahue, 2001), and that relations-oriented diversity will hamper successful team functioning. That is because relations-oriented diversity triggers stereotypes that influence the way team members think and feel about themselves as well as others on the team (Drach-Zahavy and Somech, 2002; Horwitz and Horwitz, 2007). Relations-oriented similarity, on the other hand, leads to attraction among team members, as a result of which team members experience more cohesion (Webber and Donahue, 2001). Studies on diversity, however, do not provide consistent empirical support for these theoretical notions.

Even though studies on diversity in team composition show inconsistent findings (e.g. Horwitz and Horwitz, 2007), scholars have demonstrated that diversity in team composition can have an effect on team outcomes as well as on team processes (e.g. Quinn and Restine, 1996). For instance, Jackson (1996) and Webber and Donahue (2001) indicate that diversity has important consequences for team processes including communication patterns, distribution of resources, decision-making, cohesion, and problem solving. Based on these studies, we expect diversity in team composition to also have consequences for collaborative processes between teachers. In other words, we expect diversity in team composition to have consequences for the degree of mutual engagement (i.e. through team processes related to cohesiveness, social support and friendship coalitions), degree of shared repertoire (i.e. through team processes related to communication patterns and the establishment of roles), and degree of joint enterprise (i.e. through team processes related to the acquisition of knowledge and resource distribution) that teacher teams in the school workplace demonstrate.

Until recently, little consideration has been given to the idea that various diversity attributes may operate differently in their impact on team functioning. As a reaction to this, scholars have advised that researchers should stop treating diversity as a generic concept because not all types of diversity will have a positive outcome on team performance (Webber and Donahue, 2001; Horwitz and Horwitz, 2007; Jackson, 1996). The main suggestion coming from these studies is that the content of diversity needs to be specified when it is studied. Hence, in this study we distinguish the following task-related as well as relations-oriented diversity attributes.

Task-related diversity attributes are:

- Diversity in educational level: refers to the mix of educational background of team members. This mix might enhance the breadth of perspectives, cognitive resources, and overall problem-solving capacity of the team since teachers from different educational backgrounds carry not only different knowledge but also different vocabularies, cognitive patterns and styles (Drach-Zahavy and Somech, 2002). This premise was not empirically supported in the study of Drach-Zahavy and Somech (2002).

- Diversity in tenure: refers to diversity in years on the job. Some found that diversity in tenure was positively related to successful outcomes due to the combination of experience of the long tenured with the openness and new ideas of novices. Others found negative effects of tenure diversity. It can lead to dissimilarities in attitudes and experience which may cause varied outlooks that are difficult to reconcile (Drach-Zahavy and Somech, 2002). 
- Diversity in occupational experience: refers to diversity in years of work in the educational occupation (Drach-Zahavy and Somech, 2002).

Studies do not seem to report about any empirical data on diversity in occupational experience.

Relations-oriented diversity attributes are:

- Diversity in gender: the mix of males and females in the team. The mix can hinder performance because of underlying conventions that stimulate the way team members feel, think, and interact (Drach-Zahavy and Somech, 2002). Gender diversity can result in conflict (Horwitz and Horwitz, 2007).

- Diversity in age: diversity of ages within a team. Studies indicate that interpersonal relations and interaction patterns that result from age stereotyping determine what information is available to the team, what information is addressed in the team and who has the most influence in decision making process (Turner, 1987).

There are no empirical data on age diversity (Drach-Zahavy and Somech, 2002).

The following research question was formulated:

$R Q 2$. To what degree is there a relation between task-related and relations-oriented diversity in teacher team composition and degree of mutual engagement, degree of shared repertoire, and degree of joint enterprise?

\section{Material and methods}

As a community of practice of teachers is a relatively new and complex concept, quantitative as well as qualitative data were collected, analyzed and interpreted to investigate the same underlying phenomenon (Leech and Onwuegbuzie, 2009). Data from seven teacher teams (72 teachers) in one school were gathered within a period of three months during the school year of 2008-2009.

\section{Participants}

Participant selection was based on theoretical sampling (Eisenhardt, 1989). We aimed for participants who reflected the characteristics as identified in the theoretical framework, i.e. the opportunity for ongoing collaboration and diversity in team composition. The first criterion was interdependence between teachers. This criterion was based on the assumption that ongoing collaboration requires interdependence (Little, 1990). That is, in the case of interdependence, two or more teachers have indirect control over outcomes, depending on their actions and the actions of other team members (Weick, 1979). As a result, teachers have to collaborate with each other on an ongoing basis. The second criterion was interdisciplinarity of teacher teams. This criterion was based on the reasoning that when teaming is based on interdisciplinarity with regard to subject matter, teachers with various professional and demographic backgrounds are grouped together. This resulted in the choice of a school for secondary education, which satisfied both criteria.

\section{Setting}

The setting of this study is a school for secondary education, located in a large city in The Netherlands. The seven teacher teams that participated in this study are
Communities of practice

351 
JEA

50,3

352

self-directive and responsible for approximately 100 students from one grade-level. Each team operates in its own learning domain: an open, multifunctional space where students work mainly in small groups. In the learning domains, students are educated by means of team teaching. Team teaching is a type of education in which multiple teachers work together while providing and organizing education (Main and Bryer, 2005). Consistent with the school's philosophy that teachers need to be present and accessible for colleagues and others (e.g. parents), each team has its own team room. In this team room there are facilities for preparing lessons and correcting assignments. Each team leader has a private office close to the learning domain. Team composition and team leadership are determined by the school's management. The position of team leader is a middle management function that involves additional responsibilities such as performance interviews with team members. Each team meets twice a week. On Tuesday afternoons, teams hold meetings in which they discuss students and the organization of the teaching. This team meeting is chaired by the team leader. On Thursday afternoons teams meet to develop thematic lesson material. These meetings are chaired by the "education architect", a member of the team who is officially trained in developing thematic lesson material.

\section{Instrumentation and analysis}

Degree of mutual engagement, shared repertoire, and joint enterprise. To measure the degree of mutual engagement, degree of shared repertoire and degree of joint enterprise, two perspectives were used. The first perspective was teachers' perception of the community of practice dimensions. Teacher perception related to all collaborative activities that take place between teachers in the school. The second perspective is teachers' behavior that is related to the community of practice dimensions. This behavior related to selected formal collaborative activities between teachers in the school. Team behavioral observations constitute an added value to teacher teams' self-reports.

Teachers' perception was measured using a questionnaire, developed by a team of researchers, based on the teacher community model (Admiraal and Lockhorst, 2010). Mutual engagement was measured with six items designed to assess group identity. Shared repertoire was measured with three items designed to assess shared interactional repertoire. Joint enterprise was measured with six items designed to assess shared domain. A five-point Likert scale ranging from "agree" to "disagree" was used. The response rate was 85 percent. A principal component analysis was conducted on all items with oblique rotation. The analysis showed that three components had eigenvalues over Kaiser's criterion of 1 and in combination explained 64 percent the variance. The three subscales of the questionnaire had high reliabilities: mutual engagement, $\alpha=0.90$ (example item: this team has a real team spirit), shared repertoire, $\alpha=0.74$ (example item: the communication in this team is discussed), joint enterprise, $\alpha=0.83$ (example item: differences in educational perspectives in this team are utilized).

In addition to administration of the questionnaire, video observations of the teams were performed, using an observation instrument that was developed by a team of researchers, based on the teacher community model (Admiraal and Lockhorst, 2010). For each team, two meetings were selected from a total of ten meetings that took place during the data collection period. Meetings were selected as much as possible from the 
same time period. The length of each meeting varied from one to two-and-a-half hours. In total, 14 meetings were scored using a scoring form with indicators that were rated on a three-point Likert scale. As a scoring unit consisted of one whole meeting, every indicator was scored once for each meeting. Mutual engagement was measured with four indicators designed to assess group identity:

(1) identification;

(2) multi-perspective contribution;

(3) mutual trust and responsibility; and

(4) social ties.

Shared repertoire was measured with four indicators designed to assess shared interactional repertoire:

(1) intellectual building;

(2) regulation of interaction;

(3) role taking; and

(4) dynamic effort.

Joint enterprise was measured with four indicators designed to assess shared domain:

(1) commitment to domain;

(2) common ground in concept;

(3) collective goal; and

(4) shared knowledge.

The indicators from the observation instrument are high inference measures that rely on more subjective observer judgment (Land, 1980). Context knowledge about the team was used as a means of supporting the interpretation of the observation data. The observation instrument yielded qualitative descriptions (i.e. illustrative concrete behavior) as well as quantitative scores for each indicator. Inter-rater agreement between the two raters was determined with Coefficient Kappa (Cohen, 1960), whereby $\kappa=0.66$. A level of $\kappa=0.60$ is indicated as a minimum of acceptable inter-rater agreement (Eggens and Sanders, 1993). This indicates that there is a substantial agreement between both raters.

In the analysis of the questionnaire data, the degree of mutual engagement, shared repertoire, and joint enterprise was determined by calculating mean scores for each dimension. In addition to mean scores, the standard deviation was calculated as an indication of the dispersion of scores within teams. In the analysis of the quantitative observation data, the degree of mutual engagement, shared repertoire, and joint enterprise was determined by calculating mean scores for each indicator and subsequently for each dimension. As the present study is small in scale, a classification based on value judgment was developed, resulting from an intensive discussion with a team of researchers. On a scale between 0 and 1 , the term limited was represented with a score between 0 and 0.5 , the term moderate was represented with a score between 0.51 and 0.8 , and the term strong was represented by a score between 0.81 and 1 .

With regard to the qualitative observation data, descriptions for each indicator were summarized over the collaborative team activities. This resulted in a summary of
Communities of practice

353 
JEA

50,3

354

concrete team behavior for each indicator. Subsequently, qualitative data for each indicator was grouped per dimension. Next, similarities and differences between teacher teams on each dimension were described. Qualitative observation data was used to add insight and understanding to the quantitative data.

Diversity in team composition. Data about diversity in team composition were collected with a questionnaire. The response rate was 89 percent. For the purpose of analysis, diversity in educational level was defined as deviation from exact similarity (a score of 0 indicating exact similarity and a score of 50 indicating maximum diversity within a team); diversity in tenure was defined as the standard deviation of teachers' years of work experience at the school (higher scores indicating higher diversity within a team); diversity in occupational experience was defined as the standard deviation of teachers' years of occupational experience (higher scores indicating higher diversity within a team); diversity in gender was defined as deviation from exact similarity (a score of 0 indicating exact similarity and a score of 50 indicating maximum diversity within a team); and lastly, diversity in age was defined as the standard deviation of teachers' age (higher scores indicating higher diversity within a team). In the analysis, coherence between diversity in team composition and degree of mutual engagement, shared repertoire, and joint enterprise was determined by calculating Pearson correlation coefficient, large effect size, $r=0.50$ or larger (Cohen, 1988).

The descriptives in Table I provide insight into the level of diversity in team composition within each of the teacher teams.

\section{Results}

Perceived degree of mutual engagement, shared repertoire, and joint enterprise

Results indicate that the extent in which the teacher teams perceive the community of practice dimensions is modest (Figure 1). Teacher teams' perceived mutual engagement is moderate overall, with a mean score of 0.63. Teacher teams' perceived shared repertoire is limited overall. The mean score is 0.45 . Third, teacher teams' perceived joint enterprise is moderate overall, with a mean score of 0.64 .

Observed degree of mutual engagement, shared repertoire, and joint enterprise

Quantitative results. Results show that teacher teams demonstrate the community of practice dimensions to a modest extent. Teacher teams' observed mutual engagement is strong overall. The mean score is 0.77 . Teacher teams' observed shared repertoire is

\begin{tabular}{|c|c|c|c|c|c|c|c|}
\hline & \multicolumn{7}{|c|}{ Teams } \\
\hline & 1 & 2 & 3 & 4 & 5 & 6 & 7 \\
\hline Task-related diversity attributes & & & & & & & \\
\hline Diversity in educational level & 0 & 12.5 & 10 & 42.9 & 14.3 & 0 & 46.2 \\
\hline Diversity in tenure (range: $2.4-3.9$ years) & 1.9 & 3.2 & 1.5 & 2.1 & 2.1 & 2.2 & 2.0 \\
\hline $\begin{array}{l}\text { Diversity in occupational experience (range: } 5.3-13 \\
\text { years) }\end{array}$ & 3.0 & 6.4 & 2.6 & 11.9 & 6.0 & 6.9 & .6 \\
\hline Relations-oriented diversity attributes & & & & & & & \\
\hline Diversity in gender & 30 & 37.5 & 40 & 42.9 & 14.3 & 28.6 & 30.8 \\
\hline Diversity in age (range: $33.6-46.1$ years) & 10.9 & 10.2 & 10.4 & 11.7 & 8.5 & 9.4 & 6.0 \\
\hline
\end{tabular}

Table I.

Descriptives for diversity in team composition

\section{Diversity in gender}



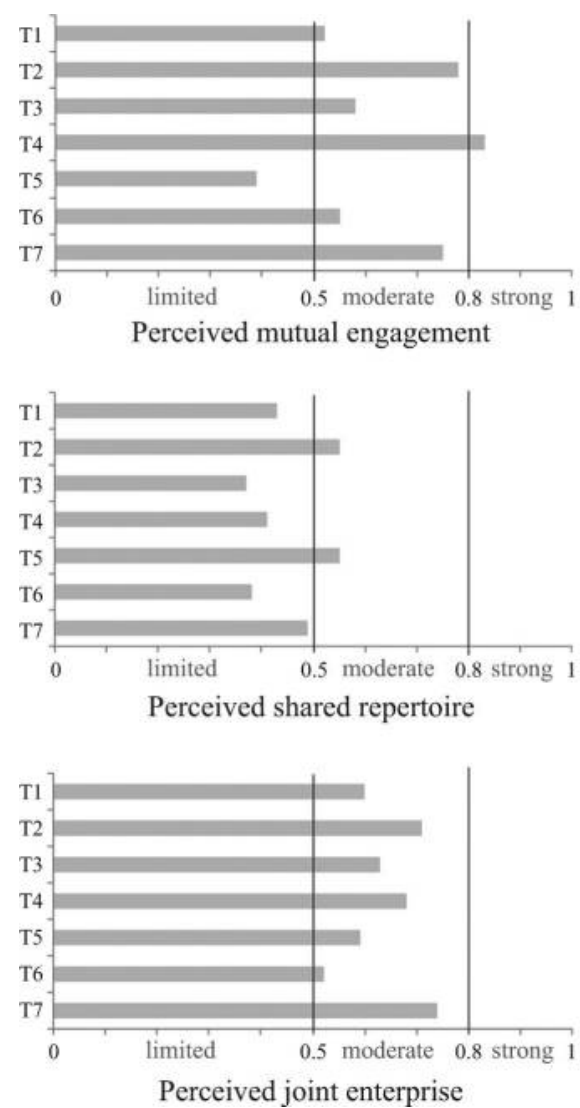

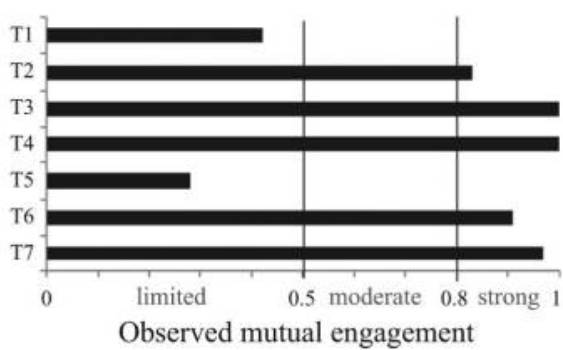

Communities of practice
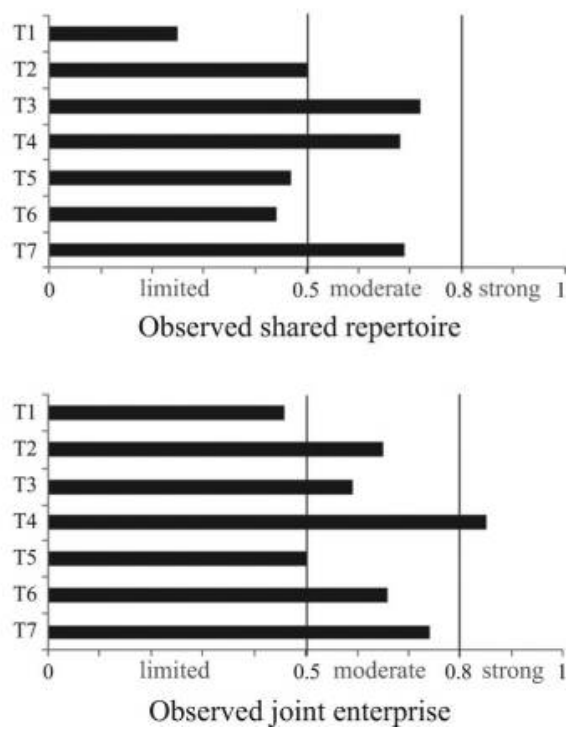

Figure 1. Mean scores for community of practice dimensions

moderate overall, with a mean score of 0.54. Last, teacher teams' observed joint enterprise is moderate overall, with a mean score of 0.64 .

To sum up, the results indicate that communities of practice actually occur in the school that was studied. However, the extent in which teacher teams perceive and demonstrate the community of practice dimensions is modest.

Qualitative results. Overall, observed mutual engagement in the teacher teams was strong. More specifically, teams that show a strong mutual engagement are teams 3, 4, and 7. Collaborative processes in team 3 can be characterized as follows. All team members belong to and have a voice in the team. Team members identify with the team as teachers primarily use the "we" perspective when they refer to or talk about the team. Team members are open to multiple perspectives during group discussions. Sometimes deviating perspectives are explicitly invited by team members or the team leader. The perspectives that are offered during discussions are mostly valued positively by team members, that is, perspectives are listened to and taken seriously. Sometimes, however, perspectives that are offered during discussions are judged or rejected without being properly considered. The atmosphere in the team is somewhat 
JEA

50,3

356 businesslike but at the same time also relaxed and friendly in a professional way. Team members make jokes during team meetings and share frequent laughs together.

Collaborative processes in team 4 are largely similar to those in team 3; however, they differ in the following respects. Perspectives that are offered during group discussions are explicitly valued by team members. Multiple perspectives are treated as enriching input to discussions. The team climate is open and team members are comfortable to share thoughts and ideas, also when they are negative. When team members open up to the group, e.g. ask for help or share a negative experience, they receive positive reactions from the team. That is, input is recognized and also acknowledged by the other team members.

Collaborative processes in team 7 are highly similar compared to the processes in team 3; nonetheless, the following differences were observed. Team members use the "I" perspective as well as the "we" perspective when they refer to or talk about the team. Different and deviant perspectives that are offered during discussions are explicitly valued positively by other team members. Also, perspectives that are offered are utilized in the discussion to reach goals or reach a decision. The team climate is open, teachers are comfortable to share ideas and experiences. When teachers open up to the group, e.g. ask for help, the reaction of the team is positive and team members show understanding for each other's problems.

Overall, the observed shared repertoires in the teacher teams were moderate. More specific, teams that show a moderate shared repertoire are teams 2,3 , and 4 . Collaborative processes in team 2 can be characterized as follows. Team members engage actively in group discussions. However, team members hardly build constructively on each other's input and arguments during discussions. Ideas from team members are often judged in a negative way. Also, emerging discussions are often cut short by the chair. The team does not discuss the regulation of the interaction, that is, the way the interaction is regulated stays implicit. The regulation by the chair is quite strict and allows team members with little space during meetings. Although it is rigid, team members accept the regulation as it is. The division of roles in the team is concentrated around existing and fixed roles in the team such as chair and secretary. Roles that team members take on are accepted by the team. During discussions, there are clearly differences in verbal effort. Some teachers are verbally more dominant than other teachers. However, these differences is verbal input are accepted by the team and they even jokes about it.

The collaborative processes in team 3 are largely comparable to those in team 2; but some processes are different. Team members mostly build constructively on each other's input and ideas during group discussions. Team members frequently ask each other positive-critical questions and often ask each other for argumentation. Team members also ground their own input with arguments during discussions.

To a large extent, processes in team 4 are similar to those in team 2; however they differ in the following respect. During team meetings, little regulation takes place. Team members do not discuss how interaction is regulated, however, the regulation is accepted by the team. The division of roles is sometimes concentrated around existing and fixed roles and sometimes team members take on roles spontaneously, for instance the role of time-keeper or the role of criticaster. Within the team, differences in verbal input during discussions are accepted. Differences in the division of tasks, on the other hand, are often not accepted. The team divides tasks equally among all team members. 
Overall, observed joint enterprise in the teacher teams was moderate. More specific, teams that show a moderate joint enterprise are teams 1, 2, and 6. Collaborative processes in team 1 can be characterized as follows. Most team members are committed to the group topic; they show involvement in the subject that is central during the discussion. Common ground with regard to central concepts that are used in discussions is not always based on agreement between all team members. The goals of the team are sometimes shared but, at the same time, individual goals also exist. During team meetings, goals are not explicitly communicated. Goals stay implicit. The team develops knowledge together, e.g. a new procedure for dealing with sick pupils. Sometimes, however, no new knowledge is developed but team members only exchange knowledge, for instance by sharing best practices.

To a large extent, processes in team 2 are similar to the processes in team 1; nonetheless, the following differences were observed. Some of the time, a small part of the team is less engaged with the central topic in the discussion. This mainly depends on teacher's disciplines and involvement in collective responsibilities. Teachers' shared understanding of concepts that are central in discussions is not discussed and stays implicit. Oftentimes, shared understanding is assumed. Team goals are mostly shared goals. Team members develop new knowledge. This knowledge or knowledge products, however, are not always based on mutual agreement among team members.

Processes in team 6 are largely similar to those in team 1; but some processes are different. All team members are committed to the subject at hand during the discussion. They are actively engaged in discussions. Possible differences in understanding of central concepts between team members are not discussed and stay implicit. Knowledge products that are developed in the team are based on mutual agreement between team members. All team members are involved in knowledge development.

\section{Relation between diversity in team composition and degree of mutual engagement,} shared repertoire, and joint enterprise

The results in Table II indicate that diversity in team composition has consequences for the degree in which teams demonstrate mutual engagement, shared repertoire, and joint enterprise. We will discuss the most prominent results.

(1) Positive as well as negative relations between the community of practice dimensions and diversity attributes were found. The relation between diversity

\begin{tabular}{|c|c|c|c|c|c|c|}
\hline & Task-rel & d diversit & ttributes & Relations-c & diversity & \\
\hline & Educational & & Occupational & & & \\
\hline & level & Tenure & experience & Gender & Age & \\
\hline Perceived & & & & & & \\
\hline Mutual engagement & 0.79 & -0.57 & -0.68 & 0.60 & 0.14 & \\
\hline Shared repertoire & 0.25 & -0.62 & -0.22 & -0.00 & 0.27 & Table II. \\
\hline Joint enterprise & 0.68 & -0.66 & -0.72 & 0.66 & -0.28 & $\begin{array}{l}\text { Relation between } \\
\text { diversity in team }\end{array}$ \\
\hline Mutual engagement & 0.44 & 0.03 & -0.78 & 0.78 & -0.47 & composition and the \\
\hline Shared repertoire & 0.71 & -0.28 & -0.40 & 0.49 & -0.42 & community of practice \\
\hline Joint enterprise & 0.77 & 0.08 & -0.62 & 0.59 & 0.05 & dimensions (Pearson's $r$ ) \\
\hline
\end{tabular}

\section{Communities of practice}

357

357


JEA

50,3

358

in tenure and occupational experience is negative while the relation between diversity in educational level and gender is positive. More specifically, the degree of mutual engagement, shared repertoire, and joint enterprise is lower when there is a more equal mix between experienced and inexperienced team members as well as a more equal mix between new and older team members. On the contrary, the degree of mutual engagement, shared repertoire, and joint enterprise is higher when there is a more equal mix between team members with a bachelor and master degree as well as a more equal mix between male and female team members.

(2) Data show that the strongest relations exist between the perceived community of practice dimensions and diversity attributes. Especially mutual engagement and joint enterprise are quite strongly related to diversity in educational level, tenure, occupational experience, and diversity in gender. An exception is age, which does not seem to be related to any dimension.

(3) The relations between the observed community of practice dimensions and diversity attributes are rather weak. However, there are some strong relations between the community of practice dimensions and diversity in educational level, occupational experience, and gender.

To conclude, the data seem to imply that higher mutual engagement, shared repertoire, and joint enterprise go together with a team composition that is characterized by diversity in educational level as well as gender, and similarity in tenure as well as occupational experience.

\section{Conclusion and discussion}

The first research question that we posed was: To what degree do teacher teams in a school for secondary education demonstrate mutual engagement, shared repertoire, and joint enterprise? Overall we can conclude that communities of practice do actually occur in a school for secondary education. The teacher teams in our study generally demonstrate modest degrees of mutual engagement, shared repertoire, and joint enterprise.

We discuss the main findings.

(1) Overall, teacher teams' degree of mutual engagement, shared repertoire, and joint enterprise is moderate. This study provides insights in the current state of affairs with regard to the occurrence of communities of practice in a school for secondary education. Within the setting of our study, communities of practice do occur in the school, although to a modest extent. However, there are two exceptions to the overall moderate ratings. Observed mutual engagement is the first exception. That is, the teams showed a strong mutual engagement when observed. This could be caused by the operationalization of mutual engagement in the observation instrument. It is possible that the indicators concern fairly superficial behavior and are less concerned with underlying feelings of belonging, being understood, and being accepted. Another possible explanation for this finding could be that during coordinated team activities, interaction between team members is quite often directed at operational affairs. For instance, teachers discuss how to organize the yearly excursion of the students. 
Mostly, these discussions stay on a superficial level and more profound matters (e.g. vision, beliefs) are not often discussed. One reason is that during coordinated team activities, teachers strive to work efficiently and conclude on time. This could mean that because of the rather superficial interactions, teams seem like cohesive social entities on the surface. Perceived shared repertoire is the second exception. That is, teams perceived this dimension as limited while it is observed as moderate. A possible explanation for this finding is that although outsiders can observe group norms, not all team members are conscious of these norms. It is possible that team members adapt their behavior to implicit group standards.

(2) Perceived and observed degree of mutual engagement, shared repertoire, and joint enterprise differ from each other. The current study shows the added value of bringing together two (methodological) perspectives on community of practice: the team members' own perceptions and the observation of team members' behavior. The first perspective can be viewed as "sense of community" and the second perspective can be viewed as "community behavior". A plausible explanation for the difference between perceived and observed degree of community is the following. "Sense of community" refers to all collaboration between team members, formal as well as informal, between all group members and between subgroups of the team. On the other hand, "community behavior" refers to a selection of formal collaborative activities. It could be argued that it matters which type of collaboration (i.e. formal or informal) is focused on. Heyl (1997) underlines the importance of taking into account both formal and informal collegial interaction between teachers. Informal collaboration and interaction between teachers has the potential of relationship building and increasing trust between teachers (Wenger et al., 2002). Furthermore, informal collaboration or interaction can open up opportunities for teachers to experiment, seek help, and discuss sensitive topics because teachers feel less pressure to perform, less loss of face as well as less judging from colleagues (de Lima, 1998). It seems that both perspectives are valuable and worth studying.

The second research question we posed was: to what degree is there a relation between task-related and relations-oriented diversity in teacher team composition and degree of mutual engagement, degree of shared repertoire, and degree of joint enterprise? We can conclude that within this study, team composition matters for the degree of mutual engagement, shared repertoire, and joint enterprise. Also, it seems relevant to distinguish between different types of diversity in the educational context.

We discuss our main finding.

(3) Team composition may be significant with regard to teacher teams' degree of community of practice. To date, school context has been largely absent in studies about team diversity. In addition, team diversity has been treated as a generic concept.

The diversity in our study was indeed a "double-edged sword". In our study, support for both diversity and similarity was found. In the school that was investigated, team diversity in educational level and gender corresponded positively with degree of
Communities of practice

359 
JEA

50,3

360 community of practice. On the other hand, team diversity in tenure and work experience related negatively to degree of teacher community. This might suggest that the teacher teams should comprise of a mix of teachers with a bachelor's and master's degree, a mix of males and females but also comprise of teachers with the same amount of years of occupational experience as well as experience at the school. The study confirms that in the current school context there is added value in distinguishing between different types of diversity.

Two aspects of our study limit its conclusions. The first aspect is the generalizability of the findings. Since a small-scale study was employed, the generalizability of our findings is rather limited. By carefully selecting appropriate cases and making explicit our selection criteria, we tried to clearly define the limits for generalizing the findings (Eisenhardt, 1989). The second aspect is the snapshot measurement in the current study. Degree of mutual engagement, shared repertoire, and joint enterprise were measured at one moment in time. However, teacher teams are dynamic and interaction patterns change. The same holds for diversity in composition. Team composition is also subject to change as teachers find other jobs, new teachers join the team or teachers get ill.

Although the notion of communities of practice is being embraced by a range of occupational fields, it has also been criticised in relation to the school organization. James et al. (2007) and Li et al. (2009) point out that by focusing on community and practice, the community of practice notion underplays the primary task. The primary task is the task that an organization must perform to survive and is - according to James et al. (2007) - vital to team functioning. The danger of not focusing on the primary task is that teams' behavior becomes directed at meeting the needs and desires of its members instead of focusing on carrying out specific tasks and assessing their effectiveness doing it (James et al., 2007). In the current study, joint enterprise was considered at a more local level instead of a meta level. This way, the joint enterprise included the tasks and goals for which the teacher teams are jointly responsible.

A second critical note comes from Yandell and Turvey (2005). Their critique is focused on the process by which newcomers become part of a community of practice, i.e. legitimate peripheral participation (Lave and Wenger, 1991). Although the community of practice notion considers newcomers to the community without experience (i.e. teachers from teacher education), it does not consider newcomers to the community that do have experience (i.e. teachers from other schools). In contrast to novice teachers, who gradually become part of a community of practice, old-timers are expected to fully participate immediately (Fuller et al., 2005). In the current study, we dealt with this potential friction by focusing on teams' flexibility towards unequal participation in discussions as well as team tasks.

Implications for theory include a more local interpretation of teams' joint enterprise in research in the school context, so that the primary task is not underplayed. Also, in addition to focussing on informal structures, researchers could focus on formal school structures in investigating communities of practice in the school.

\section{Implications and future study}

The findings of this study could serve to encourage school leaders to focus more on stimulating and sustaining communities of practice as well as the organization of 
teams in their school. The modest degree in which teacher teams in the school workplace demonstrate the dimensions of communities of practice indicates that school leaders need to support efforts to stimulate mutual engagement, joint enterprise and particularly shared repertoire. Areas of community-building efforts that school leaders could focus on are determining group goals, determining group norms, organizing group roles, stimulating a critical reflective attitude, developing mutual trust, promoting ownership, promoting perceived interdependence, and stimulating a collective memory (Brouwer et al., n.d.). School leaders can include the following aspects in their support strategy. The first aspect is to investigate what community-building efforts teacher teams already undertake. Even without support, it is possible that teacher teams already undertake community-building efforts in different areas (Brouwer et al., 2011). For instance, teams build trust by organizing informal team activities outside work. The second aspect is to build on community-building efforts that teacher teams already undertake, in other words, to build on teams' community-building repertoire. It is important to use a custom-made approach to take the needs of each team into account. The third aspect is to make existing community-building efforts more explicit with the aim to discuss, evaluate, and share efforts. It is possible that a part of community-building efforts that are undertaken are implicit (i.e. not discussed and/or unintentional). The instruments that were used in this study can be used by school leaders and teachers as self-audit tools to monitor and evaluate the development of teams' mutual engagement, shared repertoire, and joint enterprise in their school.

The findings also highlight that school leaders that aim to sustain or develop communities of practice in their school can benefit from taking diversity considerations into account. This implies that team composition should not only be focused on interdisciplinarity but school leaders should also consider educational level, tenure, occupational experience, and gender in the composition of teacher teams. In addition to organizing diverse teams, school leaders could increase teachers' joint responsibility for tasks and team performance as a way to increase teams' joint enterprise. These strategies call for increased shared leadership, i.e. decisions are not made by a single individual; rather, decisions emerge from collaborative dialogues between many individuals, engaged in mutually dependent activities (Scribner et al., 2007).

Further research can enhance our understanding of the issues that were raised in our research questions. Research focusing on longitudinal measurements of the development of communities of practice in the school workplace is recommended. This way, more insight can be gained into the stability and development of teacher teams in terms of mutual engagement, shared repertoire and joint enterprise. It would also be valuable for studies to focus on arranging and implementing principles to stimulate community building in schools. This would add to our understanding of what additional activities could be successful in increasing teacher teams' degree of mutual engagement, shared repertoire and joint enterprise. Last, future research is recommended to focus on the relation between the degree of community of practice dimensions and outcomes that are considered to be related (Vescio et al., 2008; Stoll et al., 2006), i.e. teachers' work satisfaction and efficacy or even students' cognitive and affective achievements. These lines of research could provide more in-depth insights in the development and effectiveness of communities of practice in secondary education.
Communities of practice

361 
JEA
50,3

362

\section{References}

Admiraal, W. and Lockhorst, D. (2010), “A descriptive model of teacher communities”, paper presented at the Annual Meeting of the American Educational Research Association, Denver CO, May.

Bolam, R., McMahon, A., Stoll, L., Thomas, S. and Wallace, M. (2005), "Creating and sustaining effective professional learning communities", University of Bristol, Bristol.

Bowers, C.A., Pharmer, J.A. and Salas, E. (2000), "When member homogeneity is needed in work teams. A meta-analysis”, Small Group Research, Vol. 31 No. 3, pp. 305-27.

Brouwer, P., Brekelmans, J.M.G., Nieuwenhuis, A.F.M. and Simons, P.R.J. (n.d.), "Fostering teacher community development: a review of design principles and a case study of an innovative interdisciplinary team", Learning Environments Research, to be published.

Brouwer, P., Brekelmans, J.M.G., Nieuwenhuis, A.F.M. and Simons, P.R.J. (2011), "Community development in the school workplace", paper presented at the annual meeting of the American Educational Research Association, New Orleans LA, April.

Cohen, J. (1960), “A coefficient of agreement for nominal scales”, Educational and Psychological Measurement, Vol. 20 No. 37, pp. 37-46.

Cohen, J. (1988), Statistical Power Analysis for the Behavioral Sciences, Lawrence Erlbaum Associates, Mahwah, NJ.

de Lima, J.A. (1998), "Improving the study of teacher collegiality: methodological issues", paper presented at the annual meeting of the American Educational Research Association, San Diego, CA.

Drach-Zahavy, A. and Somech, A. (2002), "Team heterogeneity and its relationship with team support and team effectiveness", Journal of Educational Administration, Vol. 40 No. 1, pp. 44-66.

Eggens, T.J.H.M. and Sanders, P.F. (1993), Psychometrie in de Praktijk (Psychometrics in Practice), CITO, Arnhem.

Eisenhardt, K.M. (1989), "Building theories from case study research", Academv of Management Review, Vol. 14 No. 4, pp. 532-50.

Fuller, A., Hodkinson, H., Hodkinson, P. and Unwin, L. (2005), "Learning as peripheral participation in communities of practice: a reassessment of key concepts in workplace learning", British Educational Research Iournal, Vol. 31 No. 1, pp. 49-68.

Hargreaves, A. and Dawe, R. (1990), "Paths of professional development: contrived collegiality, collaborative culture, and the case of peer coaching", Teaching and Teacher Education, Vol. 6 No. 3, pp. 227-41.

Heyl, E. (1997), Het Docentennetwerk. Structuur en Invloed van Collegiale Contacten Binnen Scholen (Teachers' Networks, Structure and Influence of Collegial Contact within Schools), Printpartners Ipskamp, Enschede.

Horwitz, S.K. and Horwitz, I.B. (2007), "The effects of team diversity on team outcomes: a meta-analytic review of team demography", Lournal of Management, Vol. 33 No. 6, pp. 987-1015.

Imants, J. (2003), "Two basic mechanisms for organizational learning in schools", European Journal of Teacher Education, Vol. 26 No. 3, pp. 293-311.

Jackson, S.E. (1992), "Consequences of group composition for the interpersonal dynamics of strategic issue processing", Advances in Strategic Management, Vol. 8, pp. 345-82.

Jackson, S.E. (1996), "The consequences of diversity in multidisciplinary work teams", in West, M.A. (Ed.), Handbook of Work Group Psychology, Wiley, Chichester, pp. 53-75. 
James, C.R., Dunning, G., Connolly, M. and Elliott, T. (2007), "Collaborative practice: a model of successful working in schools", Iournal of Educational Administration, Vol. 45 No. 5, pp. $541-55$.

Land, M.L. (1980), "Teacher clarity and cognitive level of questions: effects on learning”, Iournal of Experimental Education, Vol. 49 No. 1, pp. 48-51.

Lave, J. and Wenger, E. (1991), Situated Learning. Legitimate Peripheral Participation, University of Cambridge Press, Cambridge.

Leech, N.L. and Onwuegbuzie, A.J. (2009), "A typology of mixed methods research designs", Quality and Quantity, Vol. 43 No. 2, pp. 265-75.

Levine, T.H. and Marcus, A.S. (2010), "How the structure and focus of teachers' collaborative activities facilitate and constrain teacher learning", Teaching and Teacher Education, Vol. 26, pp. 389-98.

Li, L.C., Grimshaw, J.M., Nielsen, C., Judd, M., Coyte, P.C. and Graham, I.D. (2009), "Evolution of Wenger's concept of community of practice", Implementation Science, Vol. 4 No. 11, available at: www.implementationscience.com/content/4/1/11

Little, J.W. (1990), "The persistence of privacy: autonomy and initiative in teachers' professional relations", Teachers College Record, Vol. 91 No. 4, pp. 509-36.

Louis, K.S., Marks, H. and Kruse, S. (1996), "Teachers' professional community in restructuring schools", American Educational Research Iournal, Vol. 33 No. 4, pp. 757-98.

Main, K. and Bryer, F. (2005), "What does a 'good' teaching team look like in a middle school classroom?”, in Bartlett, B., Bryer, F. and Roeback, D. (Eds), Stimulating the 'Action' as Participant in Participatory Research, Vol. 2, Griffith University, Nathan, pp. 196-204.

Quinn, R.E. (1988), Beyond Rational Management, Jossey-Bass, San Francisco, CA.

Quinn, R.E. and Restine, L.N. (1996), "Interdisciplinary teams: concerns, benefits, and costs", Journal of School Leadership, Vol. 6 No. 5, pp. 494-511.

Quinn, R.E. and Rohrbaugh, J. (1981), "A comparing values approach to organizational effectiveness”, Public Productivity Review, Vol. 5 No. 2, pp. 122-40.

Seashore, K.R., Anderson, A.R. and Riedel, E. (2003), "Implementing arts for academic achievement: the impact of mental models, professional community and interdisciplinary teaming", paper presented at the 17th Conference of the International Congress for School Effectiveness and Improvement, Rotterdam.

Scribner, J.P., Sawyer, R.K., Watson, S.T. and Myers, V.L. (2007), "Teacher teams and distributed leadership: a study of group discourse and collaboration", Educational Administration Quarterly, Vol. 43 No. 1, pp. 67-100.

Shapira-Lishchinsky, O. (2009), "Israeli teachers' perceptions of mentoring effectiveness", International Journal of Educational Management, Vol. 23 No. 5, pp. 390-403.

Skerrett, A. (2010), “'There's going to be community. There's going to be knowledge': designs for learning in a standardised age", Teaching and Teacher Education, Vol. 26, pp. 648-55.

Stewart, G.L. (2006), "A meta-analytic review of relationships between team design features and team performance”, Lournal of Management, Vol. 32 No. 1, pp. 29-54.

Stoll, L., Bolam, R., McMahon, A., Wallace, M. and Thomas, S. (2006), "Professional learning communities: a review of the literature", Iournal of Educational Change, Vol. 7 No. 4, pp. 221-58.

Turner, J.C. (1987), Rediscovering the Social Group: A Self-categorization Theory, Blackwell, Oxford.

\section{Communities of practice}

363 
JEA

50,3

364

Vescio, V., Ross, D. and Adams, A. (2008), "A review of research on the impact of professional learning communities on teaching practice and student learning”, Teaching and Teacher Education, Vol. 24, pp. 80-91.

Webber, S.S. and Donahue, L.M. (2001), "Impact of highly and less job-related diversity on work group cohesion and performance: a meta-analysis", Lournal of Management, Vol. 27, pp. 141-62.

Weick, K.E. (1979), The Social Psychology of Organizing, 2nd ed., Addison-Wesley, Reading, MA.

Wenger, E. (1998), Communities of Practice. Learning. Meaning and Identity, Cambridge University Press, Cambridge.

Wenger, E., McDermott, R. and Snyder, W.M. (2002), Cultivating Communities of Practice: A Guide to Managing Knowledge, Harvard Business School Press, Boston, MA.

Westheimer, J. (1999), "Communities and consequences: an inquiry into ideology and practice in teachers' professional work", Educational Administration Quarterly, Vol. 35 No. 1, pp. $71-105$.

Yandell, J. and Turvey, A. (2007), "Standards or communities of practice? Competing models of workplace learning and development", British Educational Research Journal, Vol. 33 No. 4, pp. 533-50.

\section{Further reading}

Onwuegbuzie, A. and Leech, N.L. (2007), “A call for qualitative power analysis”, Quality and Quantity, Vol. 41, pp. 105-21.

\section{Corresponding author}

Patricia Brouwer can be contacted at: patricia.brouwer@ecbo.nl 


\section{This article has been cited by:}

1. Margot Barry, Wietske Kuijer-Siebelink, Loek Nieuwenhuis, Nynke Scherpbier-de Haan. 2016. Communities of practice: A means to support occupational therapists' continuing professional development. A literature review. Australian Occupational Therapy Journal . [CrossRef]

2. Hoi Kwan Ning, Daphnee Lee, Wing On Lee. 2016. The relationship between teacher value orientations and engagement in professional learning communities. Teachers and Teaching 22:2, 235-254. [CrossRef]

3. Michael PhillipsWorkplace Learning, Policy and Practice: Connecting Community, Practice and Teachers' Identities 29-70. [CrossRef]

4. Michael HendersonThe (Mis) Use of Community of Practice: Delusion, Confusion, and Instrumentalism in Educational Technology Research 127-140. [CrossRef]

5. Kjell Brynjulf Hjertø Business Administration, Hedmark University College, Rena, Norway Jan Merok Paulsen Business Administration, Hedmark University College, Rena, Norway Saku Petteri Tihveräinen Institute of Educational Leadership, University of Jyväskylä, Jyväskylä, Finland . 2014. Social-cognitive outcomes of teachers' engagement in learning communities. Journal of Educational Administration 52:6, 775-791. [Abstract] [Full Text] [PDF]

6. Meril Ümarik Institute of International and Social Studies, Tallinn University, Tallinn, Estonia Krista Loogma Institute of Educational Sciences, Tallinn University, Tallinn, Estonia Külliki Tafel-Viia Estonian Institute for Future Studies, Tallinn University, Tallinn, Estonia . 2014. Restructuring vocational schools as social innovation?. Journal of Educational Administration 52:1, 97-115. [Abstract] [Full Text] [PDF]

7. Sirje Rekkor, Meril Ümarik, Krista Loogma. 2013. Adoption of national curricula by vocational teachers in Estonia. Journal of Vocational Education \& Training 1-18. [CrossRef]

8. Julián López-Yáñez, Marita Sánchez-Moreno. 2013. Levers for sustainable improvement of Spanish schools in challenging contexts. Journal of Educational Change 14:2, 203-232. [CrossRef] 